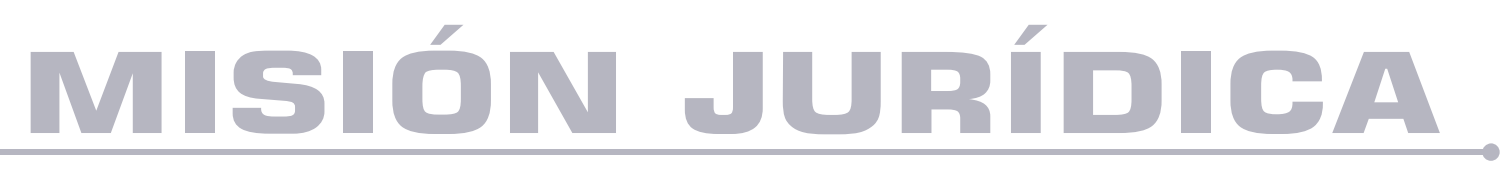

\title{
El funcionamiento del Sistema Interamericano de Derechos Humanos en tiempos de pandemia: gestión, eficacia y contexto internacional
}

The functioning of the Inter-American Human Rights System in times of pandemic: management, effectiveness and international context

Autores: Jorge Luis Silva González, Clari Neury Ramos Hernández. DOl: https://doi.org/10.25058/1794600X.1948

\footnotetext{
Ś MISIÓN JURRíDICA A
} 


\title{
EL FUNCIONAMIENTO DEL SISTEMA INTERAMERICANO DE DERECHOS HUMANOS EN TIEMPOS DE PANDEMIA: GESTIÓN, EFICACIA Y CONTEXTO INTERNACIONAL*
}

\author{
The functioning of the Inter-American Human Rights System in \\ times of pandemic: management, effectiveness \\ and international context \\ 0 funcionamento do Sistema Interamericano de Direitos \\ Humanos em tempos de pandemia: gestão, eficácia e contexto \\ internacional \\ Jorge Luis Silva González ${ }^{\text {a }}$ \\ jorgelsilva88@gmail.com \\ Clari Neury Ramos Hernández ${ }^{\text {b }}$ \\ clarita.ramos@upr.edu.cu
}

Fecha de recepción: 17 de abril de 2021 Fecha de revisión: 30 de abril de 2021 Fecha de aceptación: 18 de mayo de 2021

\section{RESUMEN}

El artículo tiene como objetivo valorar el funcionamiento del Sistema Interamericano de Derechos Humanos en función de su efectiva observancia, promoción y protección, ante la crisis sanitaria en la región a causa de la pandemia del nuevo Coronavirus. Se sistematizan los referentes históricoteóricos que fundamentan el sistema, con énfasis en su proceso de fortalecimiento y repercusión en Latinoamérica, se analiza desde el punto de vista jurídico-doctrinal el funcionamiento interno del mismo, así como su gestión y eficacia en la protección de los derechos en el contexto internacional

* El estudio se adscribe a la Disciplina de Derecho Internacional del Departamento de Derecho de la Universidad de Pinar del Río.

a. Licenciado en Derecho. Máster en Desarrollo Social. Profesor asistente de Derecho Internacional Público, Universidad de Pinar del Río, Cuba. Presidente del Capítulo Científico de la Sociedad Cubana de Derecho Internacional en Pinar del Río. Admitido en el Programa Iberoamericano de Formación Doctoral en Derecho Marítimo e Internacional por la Universidad de Cádiz, España. ORCID: 0000-0002-0214-9744

b. Estudiante de $4^{o}$ año de Derecho, Universidad de Pinar del Río, Cuba. Vinculada pre-profesionalmente al Tribunal Municipal Popular de Pinar del Río.

ORCID: 0000-0002-1087-0574 
pandémico. Dentro de los resultados obtenidos se encuentra que, a pesar de sus esfuerzos por disminuir el efecto de la pandemia, mediante la Resolución No.1/2020 de su Comisión y la Declaración No.1/2020 de la Corte, hasta la fecha han sido inevitables las violaciones de derechos debido al ascenso de la pobreza y la desigualdad, ante el desplome del rendimiento económico de la región.

\section{PALABRAS CLAVE}

Sistema Interamericano; derechos humanos; pandemia.

\section{ABSTRACT}

The article aims to assess the functioning of the Inter-American Human Rights System based on the effective observance, promotion and protection of human rights, in the face of the health crisis in the region due to the new Coronavirus pandemic. The historical-theoretical references that underpin the system are systematized, emphasizing on its strengthening process and repercussion in Latin America, the internal functioning of the system is analyzed from the legal-doctrinal point of view, in addition to its management and effectiveness in the protection of rights in the context of the international pandemic. Among the results obtained, it is found that, despite the system's efforts to reduce the effects of the pandemic through Resolution No.1 / 2020 of its Commission and Declaration No.1 / 2020 of the Court, to date the violations of rights due to the rise in poverty and inequality have been unavoidable, given the collapse of the region's economic performance.

\section{KEY WORDS}

Inter-American System; human rights; pandemic.

\section{RESUMO}

0 artigo tem como objetivo avaliar o funcionamento do Sistema Interamericano de Direitos Humanos a partir de sua efetiva observância, promoção e proteção, diante da crise de saúde na região devido à nova pandemia do Coronavírus. São sistematizados os referenciais histórico-teóricos que sustentam o sistema, com ênfase no seu processo de fortalecimento e repercussão na América Latina, analisa-se o funcionamento interno do sistema do ponto de vista jurídico-doutrinário, bem como sua gestão e eficácia no proteção de direitos no contexto pandêmico internacional. Dentre os resultados obtidos, verifica-se que, apesar de seus esforços para reduzir o efeito da pandemia, por meio da Resolução no 1/2020 de sua Comissão e da Declaração no 1/2020 do Tribunal, até o momento têm sido devidas violações de direitos. ao aumento da pobreza e da desigualdade são inevitáveis, dado o colapso do desempenho econômico da região.

\section{PALAVRAS-CHAVE}

Sistema Interamericano; direitos humanos; pandemia.

\section{INTRODUCCIÓN}

La creación de la Organización de Naciones Unidas (ONU) en 1945 representó un hito para la Comunidad Internacional en función de mantener la paz y la seguridad a escala global, fomentar entre las naciones relaciones de amistad basadas en el respeto al principio de la igualdad de derechos y a la libre determinación de los pueblos, realizar la cooperación en la solución de problemas de carácter económico, social, cultural o humanitario, así como estimular el respeto hacia los derechos humanos.

A tono con el progreso normativo y la institucionalización regional de los derechos, con la aprobación de la Declaración Universal de los Derechos Humanos (DUDH), en el continente americano se funda el Sistema Interamericano de Derechos Humanos (SIDH), el cual constituye el marco para la promoción y protección de estos y provee un recurso a los habitantes de América que han sufrido violación de los derechos por parte de un Estado. Se fundamenta en la Declaración Americana de los Derechos y Deberes del Hombre, adoptada en 1948, la Carta de la Organización de los Estados Americanos (1948) y en la Convención Americana sobre Derechos Humanos, suscrita en 1969 y vigente desde 1978.

Durante los últimos años, dicho sistema se ha comportado de manera influyente. Si bien la Comisión Interamericana de Derechos Humanos (CIDH) con sede en la ciudad de Washington D.C. y la Corte Interamericana de Derechos Humanos (CorteIDH) han atravesado momentos de crisis y enfrentado importantes desafíos, la respuesta del SIDH ante estas situaciones ha favorecido su 
fortalecimiento. Dicha respuesta se ha concretado con mayor auge en los últimos tiempos, y es que en diciembre de 2019, un brote grave de neumonía se inició en la ciudad de Wuhan, provincia de Hubei, en China, extendiéndose rápidamente con número significativo de casos y en diferentes regiones de la nación asiática, durante los meses de enero y febrero de 2020. Debido a la alta infectividad y al flujo de viajes desde Wuhan a otras ciudades de China, Asia y el resto del mundo, fue imposible contener el virus, de modo que muchos casos -aún asintomáticos- comenzaron a propagarse.

Por esta razón, la enfermedad del nuevo Coronavirus de 2019, causada por el virus SARSCoV-2, fue declarada por la Organización Mundial de la Salud (OMS) como emergencia de salud pública de importancia global y catalogada como pandemia, el 11 de marzo de 2020. Esta situación ha traído como consecuencia el incremento de la pobreza, la desigualdad y discriminación en la región americana en materia de acceso al empleo, a medicamentos, a pruebas para el diagnóstico del padecimiento, provocando millones de contagios y muertes.

En tal sentido, en el presente estudio se intenta responder las siguientes preguntas científicas: ¿Cuál ha sido el papel del Sistema Interamericano en la observancia, protección y promoción de los derechos humanos en el actual contexto de la pandemia? ¿Qué normas jurídicas se han adoptado para que los Estados miembros de la OEA respeten y creen estrategias de amparo a los derechos de los ciudadanos? ¿Qué efectos se han producido a partir del accionar de dicho sistema en función de los derechos?

Para ello, con el empleo de métodos aplicables a las Ciencias Jurídicas se persigue como objetivo: valorar el funcionamiento del Sistema Interamericano en función de la efectiva observancia, promoción y protección de los derechos humanos ante la crisis sanitaria en la región latinoamericana por la pandemia del nuevo Coronavirus.

Se tienen en cuenta los desafíos desatados en el presente siglo porque con arreglo al Derecho Internacional se pueden establecer criterios sobre cómo el Sistema ha desarrollado su mandato en la protección y defensa de los derechos humanos, con un enfoque basado en los estándares interamericanos de igualdad, no discriminación y la institucionalidad democrática. Asimismo, se analiza el factor epidemiológico por representar en la actualidad uno de los mayores conflictos que ha enfrentado la raza humana, y más aún si el mismo no tiene precedentes y viene socavando la situación económico-social de Latinoamérica.

El empleo del método histórico-jurídico posibilitó la sistematización de los antecedentes y la evolución histórica del SIDH, ante la protección brindada a los derechos humanos en la región americana, así como los asuntos más generales de su desarrollo, los retos que ha venido afrentando hasta hoy, con énfasis en el proceso de creación de sus órganos principales: la CIDH y la CorteIDH. El método jurídico-doctrinal permitió la revisión y el análisis documental de fuentes bibliográficas: artículos científicos, páginas web, libros impresos y digitales; la sistematización de los referentes teóricos-conceptuales del SIDH, así como el análisis de los mecanismos jurídicos internacionales asociados a dicho sistema.

Este es un tema que resulta pertinente en los estudios de Derecho Internacional enfocados hacia los derechos humanos. Su relevancia y actualidad científica es notable por varias razones:

- La desigualdad, la discriminación y los conflictos de institucionalidad democrática son problemas que se vienen presentando desde hace años en Latinoamérica $\mathrm{y}$, a su vez, en el funcionamiento del SIDH; por tanto, es necesario que se desarrollen propuestas doctrinales que posibiliten el trabajo de dicho sistema en aras de proteger y promover los derechos humanos en la región.

- Constituye una de las líneas de investigación priorizadas por la Sociedad Cubana de Derecho Internacional de la Unión Nacional de Juristas de Cuba referente al sistema regional de protección a los derechos, al existir escaso tratamiento e investigación de este en Cuba.

- Podría aportar claves para identificar los retos del Sistema en América, como base para la protección de los derechos humanos en el presente contexto pandémico.

\section{DESARROLLO}

1. Referentes históricos sobre el Sistema Interamericano de los Derechos Humanos: su proceso de fortalecimiento y repercusión en Latinoamérica

La Asamblea General de las Naciones Unidas (AGNU) proclama el 10 de diciembre de 1948 la 
DUDH, la cual reconoce aquellos derechos civiles, políticos, económicos, sociales y culturales que le asisten a toda persona sin discriminación por motivo de raza, color, sexo, idioma, religión, opinión política o de cualquier otra índole, origen nacional o social, posición económica, nacimiento o cualquier otra condición. Dichos derechos se desarrollaron -en lo sucesivo- en convenios significativos como el Pacto Internacional de Derechos Económicos, Sociales y Culturales (PIDESC) y, el Pacto Internacional de Derechos Civiles y Políticos (PIDCP).

Los pilares fundamentales de dicho sistema son la Comisión y la Corte Interamericanas. La primera, tiene como función principal promover la observancia y defensa de los derechos humanos en las Américas. Es un órgano principal y autónomo de la Organización de los Estados Americanos (OEA), cuyo mandato surge de la Carta de la OEA y de la Convención Americana sobre Derechos Humanos; máximo órgano de protección y promoción de los derechos en el continente. En tanto, la Corte es el tribunal de mayor rango, cuyo objetivo es la protección de los derechos humanos de los ciudadanos de América; emite sentencias y supervisa su cumplimiento en virtud de su competencia contenciosa. En las sentencias, este órgano determina si un Estado ha incurrido en responsabilidad internacional por la violación de alguno de los derechos estipulados en la Convención Americana sobre Derechos Humanos o, de otros tratados de derechos humanos aplicables al Sistema Interamericano.

Bien puede afirmarse que la historia de la especie humana es la apasionante historia de la larga $\mathrm{y}$, a veces, trágica lucha de hombres y mujeres por lograr el pleno disfrute de sus derechos fundamentales, es decir, de aquellos que les corresponden por el simple hecho de ser personas, miembros de la gran familia humana. A esos derechos se les llama hoy día derechos humanos (Tünnermann, 1997).

Los derechos humanos, definidos como derechos inherentes al hombre han sido un tema polémico que se ha venido conquistando en el decurso de la historia, siendo antecedente importante para su tutela: la Declaración Universal de los Derechos del Hombre y el Ciudadano. Así, la soberanía o la llamada jurisdicción interna de cada Estado ya no se entienden en razones de derechos humanos y no caben como argumentos para impedir la acción internacional cuando tales derechos son violados (Salvioli, 1997).
A través de la expresión derechos humanos se hace alusión de los derechos del hombre que han sido recogidos en las diversas declaraciones y pactos internacionales, garantías consagradas de manera universal e inalienable para todas las personas desde el momento en que nacen. Constituyen una categoría jurídica propia del Derecho Internacional Público; es este último el que señala cuál es el catálogo de derechos que forma parte de esta categoría, el que define los límites de su contenido, y el que les proporciona una garantía de carácter colectivo, adicional a la que ya pueda estar prevista en el Derecho interno de los Estados respecto de esos mismos derechos (Faúndez, 2004).

Una de las características resaltantes del mundo contemporáneo es el reconocimiento de que todo ser humano, por el hecho de serlo, es titular de derechos fundamentales que la sociedad no puede arrebatarle lícitamente. Son Derechos que todo Estado debe proteger. Y bien lo ratifica el presente postulado del Artículo 1 de la DUDH que, todos los seres humanos nacen libres e iguales en dignidad y derecho, y, dotados como están de razón y conciencia, deben comportarse fraternalmente los unos con los otros.

Asimismo, la Carta de las Naciones Unidas patentiza que la libertad, la justicia y la paz del mundo tienen por base el reconocimiento de la dignidad inherente a todos los miembros de la familia humana y de sus derechos iguales e inalienables, debiéndose considerar entonces que los derechos humanos, como tema y objetivo central por el cual se crea el SIDH, deben ser respetados.

Los derechos humanos afloraron con el Derecho Internacional, tras el desastre de la Segunda Guerra Mundial, dándose su violación por la injusticia misma del hombre que en búsqueda de poder, liderazgo y jerarquía, trajo para el resto de sus coterráneos, destrucción, hambre $y$, un capítulo degradante más para agregar a la historia de la humanidad. Bajo la protección del mismo Derecho Internacional serán recogidos como aquellos que posee el hombre desde que nace, como ser, declarado en sí mismo sagrado, imprescriptible y más importante aún, fuera del alcance de todo poder político. Para reponer la penosa, alarmante y trágica Segunda Guerra Mundial, se tomó como iniciativa y primera respuesta la creación de la ONU en 1948 (Canton, 2007). 
Aunque este paso constituía un avance significativo, dicha organización por sí sola y compuesta por los estados que en aquel momento la integraron, no constituía una garantía viable para la protección al ser humano. Era necesario contar con un instrumento que reconociera los derechos esenciales del ser humano, derechos que a nivel internacional no tenía, ya que solamente los Estados eran sujetos de derecho internacional (Canton, 2007).

Por consiguiente, la necesidad de contar con una normativa que reconociera los derechos humanos, culminó, aunque sería más correcto decir inició, el 10 de diciembre de 1948, con la aprobación por parte de la Asamblea General de la ONU de la Declaración Universal de los Derechos Humanos. Con esta Declaración se inició un proceso que llevó a la sanción de varios instrumentos de derechos humanos, tanto a escala universal como regional.

Para Quispe (2016) los países americanos no han sido ajenos a este proceso de formación del Derecho de los derechos humanos y, en el marco del sistema instaurado por ellos, han adoptado numerosos instrumentos relativos a la protección de los derechos humanos, a fin de que cada Estado responda por la forma como trata a los individuos sujetos a su jurisdicción.

Precisamente, en este contexto es que se debe apreciar el surgimiento del Sistema Interamericano de Derechos Humanos. Tuvo su origen en el seno de la Organización de los Estados Americanos, entidad que fue fundada por la IX Conferencia Interamericana de Estados, celebrada en la ciudad de Bogotá, en 1948. A partir de allí, la evolución y el desarrollo progresivo del SIDH se ha dado en todos los planos, normativo, orgánico y procedimental. Ese avance sistémico tuvo repercusiones positivas en el disfrute y la garantía de los derechos de las personas, sin discriminación. A nivel instrumental, comenzó con la adopción de la Declaración Americana de 1948 y en la actualidad cuenta adicionalmente con una decena de normas convencionales más otras de soft law que complementan las primeras (Salvioli, 2020).

En el campo orgánico, a la creación de la Comisión Interamericana de Derechos Humanos en 1959 le ha seguido el nacimiento de la Corte Interamericana al entrar en vigor el Pacto de San José de Costa Rica, y otros diversos órganos específicos fueron naciendo con el propósito de mejorar la aplicación de algunos de los tratados regionales en la materia (p.40).

Finalmente, en materia procedimental cabe citar a los diversos mecanismos que se fijaron por ante los dos principales órganos de tutela -la Comisión y la Corte Interamericanas-, y las progresivas reformas que dichos entes produjeron a sus normas de procedimiento reglamentos- que permitieron cada vez una mayor y más directa participación de las víctimas y sus representantes en los diversos trámites, y cumplir más adecuadamente el objeto y fin del sistema interamericano de protección de los derechos humanos (Salvioli, 2020).

El sistema se apoya actualmente en tres columnas: en primer lugar, la voluntad de los Estados, que fue crucial para la creación del sistema, y continúa siéndolo hoy en día para garantizar su funcionamiento; en segundo lugar, las instituciones de supervisión, Comisión y Corte, con una independencia y autonomía que han permitido, principalmente a la Comisión, tomar decisiones para proteger los derechos humanos, sin perjuicio de las fuertes presiones políticas de algunos gobiernos para evitarlo; y en tercer lugar, la sociedad civil, con sus inagotables recursos, para asegurarse que los Estados y las instituciones no se transformen en estructuras burocráticas, vacías de contenido, que se olviden fácilmente que el objetivo final de toda esta ingeniería es el ser humano (Canton, 2007).

Dicho sistema regional de protección de los derechos humanos cuenta, como todos los sistemas internacionales en general, con un carácter subsidiario a los sistemas nacionales, es decir, actúa como última ratio cuando los Estados han fallado en brindar la protección debida a los derechos de las personas. Esto constituye en sí una premisa fundamental, pues tanto la Corte como la Comisión, intervienen cuando se han agotado todas las vías y recursos internos que establece una nación para hacer efectiva la protección de los derechos humanos (De Martini \& Pont, 2010).

La Comisión está compuesta por siete miembros de alta autoridad moral y reconocida versación en materia de derechos humanos y representa a todos los Estados Miembros de la OEA (artículos 34 y 35 de la CADH). Cuenta con nuevas autoridades elegidas para el período 2020-2021. Su mesa directiva está integrada por José de Jesús Orozco Henríquez (México) como Presidente, Tracy Robinson (Jamaica) como Primera Vicepresidencia y Felipe González (Chile) 
en la Segunda Vicepresidencia. Cuenta además con cuatro comisionados que hacen el total de siete miembros exigibles, elegidos a título personal por la Asamblea General de la OEA. Ellos serían Dina Shelton (Estados Unidos), Rodrigo Escobar (Colombia), Rosa María Ortiz (Paraguay) y RoseMarie Belle Antoine (Santa Lucia y Trinidad y Tobago) (CIDH, 2020).

La Corte, como institución jurisdiccional autónoma, prevista para la interpretación y aplicación de la Convención Americana, está constituida por siete jueces nacionales de los Estados Miembro de la OEA, elegidos a título personal de entre juristas de la más alta autoridad moral, de reconocida competencia en materia de derechos humanos, que reúnen las condiciones requeridas para el ejercicio de las más elevadas funciones judiciales, conforme a la ley del Estado del cual sean nacionales o del Estado que los postule como candidatos.

En la actualidad cuenta con la siguiente composición: la Jueza, Elizabeth Odio Benito (Costa Rica) como Presidenta; Juez, Patricio Pazmiño Freire (Ecuador) como Vicepresidente, y como demás jueces miembros: Humberto Antonio Sierra Porto (Colombia), Eduardo Vio Grossi (Chile), Eugenio Raúl Zaffaroni (Argentina), Eduardo Ferrer Mac-Gregor Poisot (México) y Ricardo Pérez Manrique (Uruguay).

Hoy en día son treinta y cinco Estados los que forman parte de la OEA, de los cuales solo veintitrés han ratificado la $\mathrm{CADH}$, a saber: Argentina, Barbados, Bolivia, Brasil, Chile, Colombia, Costa Rica, Dominica, Ecuador, El Salvador, Guatemala, Granada, Haití, Honduras, Jamaica, México, Nicaragua, Panamá, Paraguay, Perú, República Dominicana, Suriname, Uruguay; $\mathrm{y}$ veinte han asumido la competencia contenciosa de la Corte, o sea, de los antes mencionados solo Dominica, Granada y Jamaica no están obligados a aceptar la competencia contenciosa de la Corte interamericana.

Solo veintitrés Estados se obligan a reconocer y proteger los derechos humanos recogidos en la $\mathrm{CADH} y$, solo veinte permiten que la Corte conozca de presuntas violaciones a los derechos humanos cometidos por estos veinte Estados que voluntariamente aceptaron dicha competencia. Dentro de estos no está Estados Unidos y por ende, la Corte, por ejemplo, no podría pronunciarse sobre la violación de los derechos humanos en Guantánamo, región del Estado cubano (Quispe, 2016).
Hasta la primera década del Siglo XXI, el Sistema Interamericano de Derechos Humanos fue un actor clave en importantes cambios en la situación de derechos humanos de América. Aun contando con escasos recursos y limitada capacidad de coacción, el SIDH ha permitido salvar vidas; dar voz a miles de víctimas de violaciones de derechos humanos; indemnizar a sobrevivientes y familiares; legitimar y respaldar reclamos de gran peso moral en situaciones de opresión; impulsar procesos de incorporación de valores democráticos en el discurso público en Latinoamérica; lograr la modificación de leyes y de sentencias judiciales; brindar elementos para la elaboración de legislación y políticas públicas (Nikken et al., 2007).

Sin embargo, según continúa planteando Gallón et al., (2007), aquel no ha podido dar respuesta a la mayoría de las víctimas que buscan justicia, ni ha intervenido en forma consistente en muchas situaciones críticas de derechos humanos en el hemisferio. Tampoco ha actuado con el mismo rigor frente a todas ellas, ni ha promovido el desarrollo de su labor en diversos temas y regiones.

El SIDH ha tenido una línea de actuación que, en general, se corresponde con su función tutelar de los derechos humanos. Su tendencia persistente ha sido la interpretación del derecho en el sentido más favorable a la presunta víctima, en conformidad con las normas internacionales. La composición de los órganos del SIDH por personas independientes no vinculadas formalmente con los gobiernos, es la que menos se presta a su politización. Sin embargo, los avatares del regateo diplomático han acarreado la elección ocasional de personas sin la trayectoria y el compromiso adecuados. Esto puede vulnerar la independencia e idoneidad del Sistema (Gallón et al., 2007).

Su duración y desarrollo vienen determinados por aspectos considerables, y es que desde su creación, se ha gestado y ha crecido de modo heterodoxo, respondiendo normativamente a la urgencia, actuando a la par como un sistema regional. En ese hacer, ha participado de las características del Sistema Interamericano general. Sin embargo, a diferencia de otros capítulos, el de los derechos humanos ha demostrado aptitudes de efectividad (Gallón et al., 2007).

Respecto a su proceso de fortalecimiento, debe plantearse que se ha venido comportando -hasta 
cierta etapa- de forma progresista. En los 70, sin tratado de base, la CIDH tramitó peticiones, condujo visitas in loco y produjo informes que motivaron los primeros pronunciamientos de los órganos políticos de la comunidad institucionalizada, condenando las prácticas de la desaparición forzada de personas, de la ejecución sumaria y de la tortura sistemática. En los 80, los gobiernos elegidos por las democracias reinstaladas se transformaron en los nuevos interlocutores del Sistema. Se inició un reacomodamiento en las relaciones que, tenuemente, se extendieron a la Corte Interamericana (Corte IDH). Ya para los 90, Comisión y Corte buscaron un acercamiento. La incentivación de la competencia contenciosa del tribunal y las solicitudes de medidas provisionales testimoniaron una cooperación a fomentar (Gallón et al., 2007).

Al llegar un nuevo siglo, la situación en América comenzó a verse preocupante. Lo que podría haber sido el paso a un mejor desarrollo, daba pistas de que sería todo lo contrario. El siglo XXI encuentra una América desolada por la pobreza, la exclusión y la discriminación, y junto a ello una ciudadanía social a la que no todos los gobiernos dan tratamiento adecuado (Gallón et al., 2007). La pandemia contribuyó críticamente a perjudicar y agonizar la situación que, al llegar al continente en el 2020, agravó las condiciones de este.

En este momento el SIDH es percibido como el último bastión de justicia ante la ausencia de respuesta y protección de los Estados en el ámbito interno. Esa percepción ha incrementado de manera paulatina el número de casos que se tramitan ante él. Este camino, tal como lo han evaluado algunos Comisionados y Jueces, puede conducir a su desborde y, por ende, a su ineficacia (Gallón et al., 2007).

En el presente estudio y para el análisis a desarrollar más adelante, al SIDH en lo concerniente a su estructura y funcionamiento en Latinoamérica, se coincide con el criterio de Canton (2007) y es que para una mayor efectividad en el trabajo realizado por el SIDH, los Estados deben ratificar los instrumentos internacionales de derechos humanos; cumplir con las recomendaciones de la Comisión y de la Corte, y otorgar los recursos necesarios para que la Comisión y la Corte puedan cumplir correctamente con sus funciones.

\section{Análisis jurídico-doctrinal de la estructura y funcionamiento del Sistema Interamericano de Derechos Humanos}

Desde su creación, el SIDH ha tenido como principal objetivo el de proteger y promover los derechos humanos en la región, tarea que se ha visto afectada en varias ocasiones por disimiles contratiempos, y es que los países miembros del sistema poseen como moneda corriente y habitual, las violaciones a los derechos y las libertades de sus habitantes.

Esto como bien infiere su contenido, no le provee un trabajo nada fácil al Sistema; las ejecuciones extrajudiciales en Colombia, Brasil o Guatemala; el mantenimiento de prácticas tales como la desaparición forzada de personas en Perú y El Salvador; la tortura y malos tratos en comisarías de Argentina y Bolivia; por solo poner algunos ejemplos, le imposibilita al sistema cumplir de forma eficiente los mandatos que le han sido otorgados.

Como aspectos positivos, agregar que hasta la fecha es -sin duda alguna- lo más creíble y sólido que posee la Organización de los Estados Americanos; ha logrado sobrevivir a los permanentes embates e intentos de debilitamiento de parte de gobiernos, generalmente autoritarios que, a lo largo de la historia y, en diversas épocas desearon erosionar la supervisión internacional; a ello se suma la orfandad de acompañamiento de parte de los órganos políticos de la propia OEA a la labor que desarrollan la Comisión y la Corte; los órganos de tutela se han mantenido a salvo, en general, de las pujas políticas que atraviesan permanentemente la vida de la organización; el trabajo de la Comisión Interamericana es reconocido positivamente más allá de las fronteras del continente; y finalmente, la jurisprudencia de la Corte Interamericana no solamente es de una enorme solidez jurídica, sino que ha realizado notables contribuciones al desarrollo del derecho internacional de la persona humana (Salvioli, 2020).

Con especial énfasis, ha de destacarse la incidencia e impacto directos de la labor de los órganos interamericanos de derechos humanos al interior de los Estados; muchas reformas de política pública en los países de la Organización de los Estados Americanos obedecieron a dictámenes, informes, resoluciones y sentencias ya de la Comisión, ya de la Corte Interamericana. 
La Comisión Interamericana ha desarrollado una variada gama de labores, en procedimientos flexibles, a través de sus relatorías, la realización de informes temáticos o de país, la celebración de audiencias temáticas, la promoción del mecanismo de soluciones amistosas para resolver adecuadamente una petición, la creación de mecanismos ad hoc de investigación, y los pronunciamientos públicos por medio de comunicados de prensa (Salvioli, 2020). Vale

Destacar, además, los estándares desplegados en la jurisprudencia de la Corte Interamericana. Estos han penetrado poco a poco a las instancias judiciales de los Estados parte en el Pacto de San José de Costa Rica, y de esa forma guiado la actuación de muchos de los tribunales domésticos, especialmente cortes supremas o constitucionales, y también órganos jurisdiccionales inferiores que progresivamente aplican el llamado "control de convencionalidad", cuidando que sus decisiones no legitimen normas ni prácticas que contradigan las obligaciones asumidas por los Estados al haber ratificado o adherido a la Convención Americana, u ordenando lisa y llanamente medidas para hacer efectivos los derechos establecidos en la misma (p. 41).

Se sostiene con razón que el mayor aporte que se puede ofrecer de parte de la decisión de un órgano internacional competente a una víctima de una violación a sus derechos humanos, consiste - precisamente- en garantizarle el ejercicio del derecho atropellado que ha dado origen al procedimiento ante el mismo, es decir, abortar la referida violación, eliminando la causa de esta y haciendo cesar sus efectos (Faúndez, 2004).

La recuperación del ejercicio pleno del derecho o derechos que fueron conculcados (siempre que ello es posible) primeramente tiene como objetivo inmediato el cese de la violación, para acto seguido brindar a la persona que ha sido víctima de violaciones a los derechos humanos, la posibilidad cierta de continuar su vida con la menor consecuencia posible de aquellos hechos. Esto seria, lo que según la jurisprudencia interamericana denomina, medidas de restitución, que tienen como efecto inmediato provocar el cese de la violación producida (Salvioli, 2020).

En este sentido, la Corte Interamericana ha dispuesto en una buena cantidad de casos que llegaron a su conocimiento, eliminar efectos de sentencias o resoluciones judiciales que se emitieron en violación a las normas de debido proceso, quitar antecedentes penales, volver a juzgar penalmente, o conmutar penas ( $\mathrm{p}$. 265).

Como ejemplos de dichas medidas de restitución está primero, el caso de María Elena Loayza Tamayo quien -entre otras violaciones a sus derechos- fue objeto de condena penal impuesta contra ella en el Perú, con base en violaciones al debido proceso; la víctima continuaba detenida porque tenía sentencia firme pasada en autoridad de cosa juzgada y confirmada por la máxima instancia judicial del Perú; la sentencia emitida por la Corte Interamericana ordenó su inmediata liberación, con la particularidad además que lo hizo en la decisión de fondo y sin esperar para ello la emisión de la sentencia de reparaciones que se efectuó en otra instancia procesal (Corte IDH, 1997).

Más adelante, en el caso Cantoral Benavides la Corte ordenó, también al Estado del Perú, dejar sin efecto una sentencia, y anular todos los antecedentes penales, policiales y judiciales de la víctima relacionados con el asunto (CorteIDH, 2001). En casos contra Trinidad y Tobago y Barbados, el Tribunal dispuso que no se apliquen a las víctimas decisiones judiciales basadas en leyes que consideró incompatibles per se con la Convención Americana (CorteIDH, 2009a); en otros, ordenó a Guatemala que se abstenga de ejecutar con pena de muerte a una persona, y se le juzgue nuevamente por la comisión de un supuesto delito (CorteIDH, 2005a), o aplicar otra pena alternativa sin realizar un nuevo juicio (CorteIDH, 2005b).

En un asunto costarricense, la Corte dispuso que se prive de todo efecto en una sentencia penal condenatoria, los fallos que la confirmaban, y las actuaciones judiciales para su ejecución (CorteIDH, 2004) y, en un caso contra Panamá el Tribunal ordenó al Estado dejar sin efecto la condena penal impuesta a la víctima y todas las consecuencias que de ella se deriven (CorteIDH, $2009 b$ ), medida que fue seguida en otros asuntos respecto de diversos países cuando las condenas son resultados de juicios viciados por violaciones a los derechos humanos (CorteIDH, 2017); siguiendo con dicha línea jurisprudencial, la Corte decidió más adelante que Venezuela debía dejar 
sin efecto un proceso penal militar seguido contra la víctima del caso resuelto (CorteIDH, 2009c), que debían eliminarse los antecedentes penales de dos víctimas de tortura en México (CorteIDH, 2013a); y que, el Estado argentino debía dejar sin efecto la condena civil impuesta a dos periodistas en el marco de un caso en que determinó la violación a la libertad de expresión (CorteIDH, 2013b).

La orden de cumplir sentencias dictadas en el fuero interno se reiteró en diversos asuntos respecto de Perú: en el caso Muelle Flores el Tribunal Interamericano, indicó que debía cumplirse con la ejecución de las sentencias internas que beneficiaban a la víctima, así como garantizarle de manera efectiva el pago de la pensión y mantener el pago provisional de la misma y el acceso al seguro social de salud (CorteIDH, 2019a); por su parte, en el caso de la Asociación Nacional de Cesantes y Jubilados de la Superintendencia Nacional de Administración Tributaria, la Corte ordenó ejecutar una sentencia de la Sala de Derecho Constitucional de la Corte Suprema de Justicia en relación al pago de pensiones (CorteIDH, 2019b). De hecho,

Las reparaciones ordenadas por la Corte Interamericana en la resolución de los asuntos que han llegado a su conocimiento no solamente han dado respuestas a las víctimas en el sentido de la restitución de derechos o la compensación económica sustitutiva en caso de restitución imposible, sumadas naturalmente a las reparaciones pecuniarias que derivan de todo daño provocado bajo los rubros de daños materiales e inmateriales; el Tribunal ha desarrollado una importante batería de medidas complementarias, dirigidas a las víctimas en el plano personal -medidas de rehabilitación- o con efectos claros hacia el espacio público (Salvioli, 1997, p. 41).

A la par de los aspectos positivos, se encuentran las deficiencias. Los méritos del Sistema Interamericano son incuestionables. Sin embargo, la pregunta es si son suficientes y aceptables. En su opinión la respuesta es negativa. Da la impresión de que el Sistema se ha vuelto esclerótico y frecuentemente desfasado frente a las realidades y necesidades del hemisferio (Gallón et al, 2007).
Varias razones explican esta afirmación, y coincidiendo con el criterio de Gallón et al., (2007), puede afirmarse que las causas que lo justifican son: por un lado, la Comisión Interamericana (CIDH) no ha logrado desprenderse de la imagen de parcialidad frente a los Estados y, curiosamente, en ocasiones también frente a las víctimas. Las tensiones que existen entre la $\mathrm{CIDH}$ $\mathrm{y}$ los restantes actores son desproporcionadas y muy dañinas. A su vez, los Estados en general se niegan a dotar, sobre todo a la Comisión, de las herramientas necesarias $y$, especialmente, de la confianza requerida.

Otro de los retos del Sistema que constituyen a su vez preocupaciones regionales, de carácter político, pero con un enorme impacto en materia de derechos humanos, es el debilitamiento democrático en la región. Durante algunos años, casos como el Golpe de Estado en Honduras, en el 2009, la destitución del presidente Lugo en Paraguay en el 2012; o la destitución de la presidenta Rousseff en Brasil en 2018, parecerían más bien recursos de un pasado golpista que se niega a morir en las Américas. Empero, los procesos venezolano y nicaragüense que han transitado desde la democracia hacia un creciente autoritarismo, junto a las recientes crisis sociales en Ecuador, Chile y el golpe de estado en Bolivia (todas en 2019), que han devenido en graves crisis de derechos humanos, han demostrado la fragilidad de los sistemas democráticos y la vigencia en la región de las tendencias autoritarias (Nash, 2020).

Por otra parte, el otrora gobierno de Trump ahora gobierno de Joe Biden- en Estados Unidos y de Bolsonaro en Brasil, son una evidente amenaza a la idea democrática y a la vigencia de los derechos humanos que, por el poder e influencia de ambos países en la región, preocupan en términos políticos y de derechos humanos (Nash, 2020).

El SIDH opera en el seno de la Organización de los Estados Americanos (OEA), que es un organismo políticamente polarizado y en permanente crisis financiera. Dicha organización ha renunciado constantemente a ejercer su función de garante colectivo del sistema que sus propios miembros crearon. Debido a ello, no es previsible que la Comisión o la Corte vayan a recibir el apoyo necesario para ejercer su mandato de manera adecuada. Por lo tanto, estos 
órganos, y en particular la Comisión, continuarán dependiendo de donaciones de algunos Estados para desarrollar las actividades más esenciales, lo cual no es saludable. Esta es posiblemente una de las mayores debilidades del Sistema (Gallón, et al., 2007).

Según Ibáñez (2021) el SIDH tiene enormes ventajas. Las más importantes son su vocación y su experiencia. Por ello, precisamente, es necesario debatir sobre los serios retos existentes que imposibilitan su correcto funcionamiento $y$, por tanto, se convierten en trabas al momento de ejercer la adecuada protección y promoción de los derechos humanos en la región. Mencionar principalmente, al destacar por su complejidad:

- La universalización de los tratados interamericanos: Mientras siga existiendo por parte de los Estados, la falta de ratificación universal a los instrumentos del SIDH, y la división en dos sub-grupos, entre aquellos que han aceptado y los que no han aceptado la competencia contenciosa de la Corte IDH, se seguirá generando grados diferenciados de ratificación que 'coloca a millones de personas en una situación de desventaja en cuanto al grado de protección internacional de los derechos", como lo señala la CIDH.

-El plazo razonable del proceso interamericano: Este plazo, que se desprende de la CADH y de la jurisprudencia interamericana no solo es aplicable a los procesos internos dentro de los Estados, sino también a los procedimientos ante los tribunales regionales e internacionales de derechos humanos. Por ende, los órganos del SIDH, hacen grandes esfuerzos por reducir los plazos en la solución de peticiones, casos y situaciones sometidos a su competencia. Esto posibilita un aumento en la productividad de los órganos del SIDH, la resolución de solicitudes de medidas cautelares en tiempo oportuno, la agilización del estudio inicial de peticiones, el trámite de casos y peticiones, así como el seguimiento de los asuntos en solución amistosa.

-El cumplimiento de las decisiones de los órganos interamericanos: Tal como ha sido reiterado por la jurisprudencia interamericana, en el marco del derecho de acceso a la justicia, la efectividad de cualquier decisión depende de su ejecución. En 2019, la CIDH aprobó las Directrices Generales de Seguimiento de Recomendaciones y Decisiones, para fortalecer sus acciones de seguimiento. Por su parte, la Corte IDH, desde 2015, ha puesto en funcionamiento la Unidad de Supervisión de Cumplimiento de Sentencias, con el fin de dar mayor seguimiento al cumplimiento de las reparaciones por parte de los Estados. Lo anterior revela la imperiosa necesidad de una actuación estatal coherente, conforme a los principios de pacta sunt servanda y de buena fe, exigibles por el Derecho Internacional Público.

-Los alcances del control de convencionalidad respecto a su aplicación por toda autoridad pública: A la fecha, parecen superados los cuestionamientos respecto a que todo Estado Parte de la CADH está obligado a realizar el control de convencionalidad. Sin embargo, aún queda pendiente que se afiance la idea de que dicho control de convencionalidad no solo vincula a las autoridades del Poder Judicial y demás órganos vinculados a la administración de justicia en todos los niveles, sino a toda autoridad pública, en ejercicio de sus competencias y de las normas procesales vigentes en el derecho interno.

Respecto al tema, se comparte el mismo criterio abordado por Ibáñez Rivas, y es que exigir que toda autoridad pública actúe de conformidad a la CADH y a la jurisprudencia interamericana es consecuencia lógica de la aplicación del derecho internacional público y del derecho internacional de los tratados. Si un Estado es parte de un tratado, éste vincula a todos sus poderes, órganos $\mathrm{y}$ autoridades, los que en definitiva pueden generar la responsabilidad internacional de aquél.

- Desafíos de la justicia desarrollada durante la pandemia: Frente a la pandemia de COVID-19, los dos órganos del SIDH se pronunciaron inmediatamente, recordando a los Estados sus obligaciones internacionales en materia de derechos humanos, aún en contexto de crisis sanitaria: la CIDH a través de la Resolución 01/20 "Pandemia y Derechos Humanos en las Américas" y la Corte IDH, mediante la Declaración 01/20 "COVID-19 y derechos humanos: los problemas y desafíos deben ser abordados con perspectiva de derechos humanos y respetando las obligaciones internacionales.

A lo largo de su historia, fueron incontables los logros del Sistema Interamericano. Sin perjuicio de ello, en la actualidad se ve interpelado por diferentes obstáculos y desafíos que deben 
encararse y superarse, con el objetivo último de garantizar el respeto de los derechos humanos y de crear institucionalidad democrática en países castigados por dictaduras, regímenes autoritarios, conflictos armados internos y altísimos índices de pobreza, discriminación y violencia (Gallón et al., 2020)

Como bien se explicará más adelante y en relación con lo anterior, se hacen urgentes y necesarias las soluciones para la situación que encara América en la actualidad; el coronavirus lo ha interpuesto y la población latinoamericana, en especial la de zona de medios ingresos, lo exige. Con esto y la previsión de un colapso económicosocial sin retroceso, se hace válido coincidir con el criterio de Ibáñez (2021) y es que ciertamente los retos del SIDH lo interpelan en cuanto al pleno respeto y garantía de los derechos humanos de toda persona en la región. Interpelan también a los Estados y, finalmente, a la academia, las organizaciones no gubernamentales y a la sociedad civil, quienes deben mantener más vivo que nunca el interés por participar en el SIDH, a través del litigio, la presentación de información, la organización de espacios de debate, monitoreo y seguimiento.

3. Trascendencia económico-social de la pandemia en la región latinoamericana: gestión y eficacia de los órganos del Sistema Interamericano ante el nuevo Coronavirus

El 31 de diciembre de 2019, el Ministerio de Salud de China informó a la OMS sobre 41 pacientes con neumonía atípica grave, la mayoría de ellos relacionados con el mercado de comida de mariscos y animales exóticos en la ciudad de Wuhan, en la provincia de Hubei en China (Dong \& Gardner, 2020).

Desde los primeros casos reportados en Wuhan, China, la expansión local y finalmente mundial llegó rápidamente a niveles alarmantes. Infortunadamente, debido a la alta infectividad y al flujo de viajes desde Wuhan a otras ciudades de China, Asia y el mundo, fue imposible contener el virus, de modo que, muchos casos aún asintomáticos comenzaron a propagarse (Wu \& McGoogan, 2020).

Razón por la cual, el 30 de enero de 2020, la OMS declaró al COVID-19 como «emergencia de salud pública de alcance internacional», y el 11 de marzo con 37,364 casos reportados fuera de
China, se catalogó oficialmente como "pandemia» (Dunlop; Howe; Li D; Allen; 2020). El COVID-19 llegó a América Latina y el Caribe el día 25 de febrero de 2020, cuando el Ministro de Salud de Brasil confirmó el primer caso, desde entonces, se ha presentado una propagación masiva en la región (Sánchez, Arce \& Rodríguez; 2020).

Durante todo el período en el que se ha manifestado la COVID-19, desde su aparición en diciembre de 2019, la preocupación de las naciones ha sido alarmante, puesto que la pandemia no traería consigo solo avasalladoras pérdidas humanas, como lo ha hecho hasta la fecha, al registrar más de un cuarto de millón de muertes, sino también, en una escala de prioridades, consecuencias económicas causadas por las medidas de confinamiento y la recesión mundial.

Los gobiernos de la región han mostrado reacciones muy dispares frente a la amenaza del virus: mientras algunos países, como Argentina, Perú, Colombia o Bolivia declararon, de manera preventiva, un amplio estado de alarma tras unos pocos casos confirmados, otros países, gobernados por populistas, como México y Brasil, adoptaron tarde medidas de poco calado para mitigar los efectos de la COVID-19 (Filgueira, et al., 2020).

La Comisión Económica de las Naciones Unidas alerta que alrededor de un tercio de la población de América Latina podría caer por debajo del umbral de la pobreza a causa de la crisis del coronavirus. Para los cerca de 650 millones de personas que viven en la región, de las cuales la mayoría trabajan en la denominada «economía informal» y no cuentan con ayudas públicas, esta pandemia puede convertirse en una cuestión de supervivencia, incluso sin altos niveles de contagio.

Ante el acercamiento de las consecuencias previstas por el coronavirus -que se vienen sintiendo desde hace varios meses, desde su declaración oficial como pandemia- se ha trabajado en la creación de una vacuna, que de una vez y por todas ayude detener la ola de contagios y de fallecimientos que ha traído consigo. El cierre del 2020 aproximó la esperanza de darle un fin al coronavirus, pero a pesar del desarrollo de vacunas en un tiempo récord, la población 
mundial se encuentra ahora en un momento complicado.

Han aparecido nuevas variantes del virus que se contagian más eficazmente $y$, para complicar más la situación, las empresas productoras de vacunas están teniendo dificultades para responder a la demanda mundial. Actualmente se están administrando en el mundo 5 vacunas, 3 de ellas (Pfizer, Moderna, AstraZeneca) aprobadas por organismos independientes, y las otras 2 producidas por organismos estatales de Rusia y China, y administradas en otros países, pero sin una evaluación externa (Cañelles; Jiménez \& Campillo; 2021).

Ciertamente, la vacuna contra la COVID-19 llegó como una promesa de rescate para la raza humana, pero en las últimas semanas ya es el símbolo más contundente de la desigualdad, y es que el tener o no la vacuna, es la mejor forma de darle vida a esta categoría en el año que apenas inicia; y Latinoamérica, que tiene consigo desde hace tiempo la etiqueta de "región más desigual del mundo", lo está descubriendo.

Más allá de los mensajes previos que apuntaban a un acceso universal a las vacunas, la realidad muestra otra cara: los países con mayores recursos han acaparado las primeras dosis y el resto lucha por asegurar sus primeras inyecciones. Es en ese preciso segundo grupo en el que están la mayoría de los países de América Latina, donde la vacunación ha iniciado de manera irregular y a cuentagotas. Por ejemplo, son solo México, Chile, Costa Rica y Argentina las únicas naciones que han comenzado la inoculación, con apenas unos miles de personas y sin indicios firmes sobre cómo continuará (Cué, 2021).

Todo este panorama desigual se debe a lo que expertos y la prensa internacional denomina "nacionalismo de vacunas"; y es que no existe un sistema global de distribución de las vacunas. Cada país negocia por su cuenta con las farmacéuticas, y he ahí el principal y grave problema para América Latina, que está en tierra de nadie, porque tiene muchos países en la zona de ingresos medios. No es lo suficientemente rica para cubrir de forma rápida a toda su población, ni lo suficientemente pobre como para depender de la solidaridad.

Por otra parte, es conocido que una considerable parte de la pobreza del mundo se encuentra repartida geopolíticamente en la región latinoamericana y que, desde la aparición de la pandemia, ha agudizado y sobresaltado notoriamente. Naciones que la integran no pueden comprar las vacunas necesarias para poder combatir la COVID-19 porque se encuentran en zonas de ingresos medios, y ni pensar siquiera en negociaciones bilaterales con las compañías desarrolladoras porque sus recursos carentes no le permiten entablar estos pactos, quedando así bajo una relegación casi absoluta de acceso a las vacunas, y dependiendo de la beneficencia del programa COVAX para poder garantizar el bienestar de una parte de sus habitantes.

Esta situación del continente no brinda una imagen nada positiva, que ya de por si se ha visto dañada por la administración y dirección de los jefes de algunos Estados de la región- como Brasil con Bolsonaro, Ecuador con Moreno y Colombia con Iván Duque- y que no brota con la aparición de un virus mortal, sino que se hizo peor, porque ya, por desgracia para la población latinoamericana, se encontraba considerablemente indigente.

Tres son los desafíos estructurales que caracterizan la singularidad y la especificidad de la región latinoamericana, según Piovesan (2020):

1) La profunda desigualdad económica y social;

2) El patrón histórico de discriminación contra grupos en situación de vulnerabilidad; $\mathrm{y}$

3) Los dilemas de la institucionalidad democrática. Desafíos estructurales que, como se explicaba con anterioridad, aunque ahora son gravemente notorios, no son nuevos, sino que se ven exacerbados, acentuados y agravados por el impacto del COVID-19.

Desde una perspectiva étnico-racial, aproximadamente el $25 \%$ de la población Latinoamericana es afrodescendiente. Los indicadores sociales demuestran el sistemático, histórico y estructurador patrón de discriminación, exclusión y violencia que afecta a los grupos afro e indígenas en la región, así como las mujeres, los niños y niñas están sujetos a formas múltiples de discriminación (overlapping discrimination). Como afirma Michelle Bachelet, 
"el virus no es discriminatorio; pero su impacto lo es" (Piovesan, 2020).

Tanto las Américas como el mundo entero se han venido enfrentando a una emergencia sanitaria sin precedentes ocasionadas por el coronavirus, adoptando para su combate medidas desafiantes, ya sea en términos de políticas y medidas sanitarias, como en capacidades económicas, lo que ello no implica que estas medidas de atención y contención urgentes obvien el pleno respeto a los derechos humanos, las libertades fundamentales y la protección efectiva a sus poblaciones como bien lo establece y demanda la Declaración Universal de los Derechos Humanos.

El Pacto Internacional de Derechos Civiles y Políticos (PIDCP), exige y establece que las restricciones a los derechos por razones de salud pública o emergencia nacional sean legales, necesarias y proporcionales; la cuarentena obligatoria $\mathrm{o}$ el confinamiento de personas sintomáticas deben, como requisito mínimo, llevarse a cabo de conformidad con la ley. Deben ser medidas estrictamente necesarias para lograr un objetivo legítimo, basarse en evidencia científica, ajustarse al principio de proporcionalidad para lograr ese objetivo, no aplicarse de manera arbitraria ni discriminatoria, tener duración limitada, ser respetuosas con la dignidad humana y estar sujetas a revisión (Naciones Unidas, 2021).

Es en este escenario donde la pandemia presenta la mayor prueba para la Democracia y el Estado de Derecho en la región, teniendo en cuenta que, bajo el argumento de que "los tiempos excepcionales demandan medidas excepcionales", con el Poder Ejecutivo fortalecido y con un mayor protagonismo de las Fuerzas Armadas, existe el riesgo de abuso y arbitrio en la restricción de los derechos y libertades fundamentales, bajo la excusa de luchar contra la COVID-19.

Ante ese contexto político, social y cultural, la Comisión Interamericana de Derechos Humanos (CIDH) comenzó a desarrollar su mandato transformador en la protección y defensa de los derechos humanos, con un enfoque basado en los estándares interamericanos, siempre centrado en las víctimas, en el resguardo de su dignidad y en la prevención de su sufrimiento. El sistema interamericano tiene la potencialidad de contribuir al fortalecimiento de los derechos humanos, a la democracia y al Estado de Derecho en la región más desigual y violenta del mundo (Piovesan; 2020).

Para monitorear el impacto en los derechos humanos de las poblaciones y grupos en situación de vulnerabilidad en el contexto de la pandemia, en los 35 países de la región, el 27 de marzo de 2020, la CIDH anunció la instalación de su Sala de Coordinación y Respuesta Oportuna e Integrada a la crisis en relación con la pandemia del COVID-19. El balance, el impacto y los resultados alcanzados se presentan en el Comunicado de Prensa del 16 de mayo del mismo año.

Ya para el 10 de abril de 2020 la CIDH había aprobado la Resolución No.01/2020 sobre "Pandemia y Derechos Humanos", con 85 recomendaciones a los Estados, a la luz de los estándares interamericanos y del principio pro persona. Esta realza el deber de los Estados de adoptar el enfoque centrado en los derechos humanos en toda estrategia, política o medida estatal de enfrentamiento a la pandemia de COVID-19 y sus consecuencias, con la debida observancia de la universalidad, indivisibilidad, interdependencia e interrelación de los derechos; la igualdad y no discriminación; la perspectiva de género, diversidad e interseccionalidad; la inclusón; la accountability; el respeto al Estado de Derecho; y el fortalecimiento de la cooperación entre los Estados.

En el caso de la Corte IDH, como órgano de protección de los derechos humanos, consciente de los problemas y desafíos extraordinarios que los Estados americanos han estado afrontando, debido al impacto de la pandemia, emitió el 9 de abril de 2020 una declaración a fin de instar que las medidas y acciones a implementar para contrarrestar el coronavirus se efectuase en el marco del Estado de Derecho y respetando a los mecanismos internacionales creados para la protección de los derechos humanos y los estándares desarrollados en la jurisprudencia de su Tribunal.

Así, se infiere que ante el impacto de la COVID-19 los dos órganos del SIDH, tanto la CIDH como la CorteIDH, se han pronunciado de manera efectiva y alífera en aras de incentivar el combate contra la pandemia, la primera ante la Resolución y la segunda mediante la Declaración, ambas 
son nominadas con el No. 1 de 2020. Si bien son diferentes solo en ámbito de competencia y jurisdicción, ambas reconocen la complejidad que enfrentan los Estados y las sociedades en todo el mundo debido a las medidas excepcionales que buscan responder a la pandemia ocasionada por el coronavirus, pero también que dentro de todo este andamiaje complejo se debe dar plena garantía a los derechos humanos.

En el caso de la Resolución No. 1 de 2020, fue dictada en ejercicio de las funciones que le son conferidas a la CIDH por el artículo 106 de la Carta de la Organización de los Estados Americanos y en aplicación del artículo 41.b) de la Convención Americana sobre Derechos Humanos y el artículo 18.b) de su Estatuto, teniendo así como objetivo el de responder a los tres desafíos estructurales, ya mencionados, de la región: desigualdad económica y social, discriminación contra los grupos más vulnerables y, el conflicto de la institucionalidad democrática; todo a través de recomendaciones a los gobiernos, que resaltan los deberes y obligaciones internacionales de los mismos en materia de derechos humanos.

Respecto al desafío estructural de la ilimitada desigualdad, la Resolución potencia los derechos económicos, sociales, culturales y ambientales, exigiendo a los Estados que den especial prioridad a la protección de los derechos a la vida y la salud, mediante la adopción de medidas inmediatas y urgentes, con la debida diligencia, respaldando el deber del Estado de prevenir y mitigar los daños, y poniendo a disposición el máximo de los recursos disponibles para la efectividad del derecho a la salud.

Se destaca que la protección del derecho a la salud (física, psíquica y mental) debe incluir sus determinantes básicos y sociales, a comprender el derecho al agua potable, a la alimentación y a una vivienda adecuada, incluyendo también la protección social a través de subsidios, renta básica y otras medidas de apoyo económico. Enfatiza el derecho a acciones, programas y políticas públicas basadas en la mejor evidencia científica, mediante procedimientos transparentes, independientes, participativos, claros e inclusivos. También es necesario mencionar el deber de los Estados de exigir y fiscalizar que las empresas respeten los derechos humanos.
En lo que tañe al desafío estructural de la discriminación histórica, la Resolución No.01/2020 presenta relevantes recomendaciones dirigidas a los grupos en especial situación de vulnerabilidad, enfatizando el deber reforzado de protección estatal a las personas mayores, las personas privadas de libertad, las mujeres, los pueblos indígenas, las personas migrantes y refugiadas, los niños, niñas y adolescentes, las personas Lesbianas, Gay, Bisexual, Transexual e Intersexual (LGBTI), los afrodescendientes, y las personas con discapacidades.

En cuanto al desafío estructural relacionado con los dilemas de la institucionalidad democrática, la Resolución exige de los Estados que en cualquier restricción de derechos y libertades se observen estrictamente los principios de legalidad, proporcionalidad y temporalidad, para cumplir con las finalidades legítimas de proteger la salud. Reafirma la importancia del funcionamiento de los poderes, sobre todo, los procedimientos judiciales idóneos para la protección de derechos y libertades, así como la garantía de los derechos a la libertad de expresión y el acceso a la información, siendo estos pilares esenciales del régimen democrático (Resolución No.01/2020).

Respecto a la Declaración No. 1/2020 dictada por la Corte, plantear que su contenido no dista de lo recogido en la Resolución de la CIDH, y es que dicha Declaración también considera que todos los conflictos y desafíos extraordinarios que ocasiona la presente pandemia deben ser abordados a través del diálogo y la cooperación internacional, siendo el multilateralismo esencial para coordinar los esfuerzos regionales para contener la pandemia (Corte IDH, 2020).

Todos los organismos multilaterales, sin importar cuál sea su naturaleza, deben ayudar y cooperar con los demás Estados de manera conjunta para así solucionar los agravios que ha traído, trae y continuará, trayendo la pandemia, siempre bajo un enfoque de derechos humanos, así como también que los funcionarios que velan por el cumplimiento de la ley se ajusten a los principios de absoluta necesidad, proporcionalidad y contención de acuerdo a la jurisprudencia de la Corte Interamericana al momento de utilizar la fuerza como medida de orden y disciplina (Piovesan, 2020). 
Finalmente, la Corte insta porque se preserven las fuentes de trabajo y se respeten los derechos laborales de todos los trabajadores y trabajadoras, el acceso a la información veraz y fiable, así como a internet y que se garantice el acceso a la justicia y a los mecanismos de denuncia, así como se proteja particularmente la actividad de los periodistas y las defensoras y defensores de derechos humanos. Pone en alerta a los órganos o dependencias competentes para combatir la xenofobia, el racismo y cualquier otra forma de discriminación (Declaración No. 1/2020).

Vale el reconocimiento al intento del SIDH por amortiguar el golpe de la pandemia, mediante la Resolución No.1/20 y la Declaración No.1/20, pero la situación actual señala que sus Estados miembros han hecho caso omiso a las orientaciones y declaraciones hechas por el Sistema. Los índices de contagios y fallecidos por día crecen alarmantemente; y aunque la intención es buena, los esfuerzos por cumplirla se hacen utópicos.

Las adversidades para las y los migrantes se exacerban, como la inmovilidad que les afecta, los riesgos ante la pérdida del empleo, la disminución del empleo doméstico remunerado entre las mujeres, la sobrerrepresentación de las trabajadoras y los trabajadores migrantes en las labores de primera línea, las detenciones indefinidas, la falta de acceso expedito a la documentación necesaria para recibir atención médica, las condiciones habitacionales deficientes y la estigmatización de las personas retornadas en las comunidades de origen, especialmente de las que retornan de los Estados Unidos; continúan presentes en la realidad de Latinoamérica (CEPAL, 2020).

Han desaparecido millones de empleos, especialmente en el sector informal, donde la mayoría de los trabajos requieren de un continuo contacto físico. Los grupos de población más afectados han sido las mujeres, los jóvenes y los trabajadores con una educación más limitada, quienes constituyen la mayor parte de los empleos en sectores como el comercio al por menor o la hostelería. Las pérdidas de empleo e ingresos han provocado que millones de personas de América Latina y el Caribe se hayan visto obligadas a caer en la pobreza, lo que ha acabado con cualquier progreso alcanzado en estos últimos 15 años.
Según expone el Informe de la Comisión Económica para América Latina y el Caribe (CEPAL), la recuperación sostenida tras la pandemia dependerá no solo del alcance de las medidas de estímulo y la rápida introducción de las vacunas, sino también de la calidad y la eficacia que tengan esas medidas para aumentar la resiliencia contra las futuras crisis. En este escenario, si el trabajo se ejecuta con responsabilidad, el SIDH puede provocar cambios positivos, logrando la integración de sus órganos para con los Estados, y obtener entonces un eficiente combate contra la crisis económica y sanitaria que enfrenta actualmente América Latina (2021).

El avasallador impacto del COVID-19 y su naturaleza multidimensional fomentan un tiempo de profunda transformación y reinvención, marcado por decisiones cruciales; y compartiendo el criterio de Piovesan (2020), habrá un mundo pre-COVID y un mundo post-COVID. En su esencia, la pandemia advierte que compartimos las mismas amenazas, miedos y riesgos, pero también advierte que compartimos la misma humanidad y la capacidad resiliente de construir y reconstruir sociedades más inclusivas, sostenibles, justas y solidarias, en las que todos y todas sean libres e iguales en dignidad y derechos.

\section{CONCLUSIONES}

El SIDH se erige en el marco de la OEA a través de diferentes instrumentos normativos, entre los cuales se ubican preferentemente la Declaración Americana sobre Derechos y Deberes del Hombre y la Convención Americana sobre Derechos Humanos. Este sistema reconoce un catálogo de derechos básicos con fuerza obligatoria para los Estados que lo componen, a la vez que instituye órganos que velan por su cumplimiento. La Comisión Interamericana de Derechos Humanos y la Corte Interamericana de Derechos Humanos constituyen los grandes pilares del Sistema y, en el marco de sus funciones y atribuciones, colaboran con la efectiva promoción y satisfacción de los derechos humanos en el hemisferio.

El siglo XXI encuentra al SIDH consolidado desde el punto de vista de su producción jurídica y sus métodos de trabajo; sin embargo, muchos aspectos que le rodean hacen que su funcionamiento se encuentre en crisis, entre ellos cabe mencionar, el enorme retraso en el 
tratamiento de las peticiones individuales en la Comisión Interamericana; la reticencia de los Estados a cumplir con las medidas cautelares dispuestas por la misma, cuestionando su obligatoriedad jurídica; la $\mathrm{CIDH}$ no ha logrado desprenderse de la imagen de parcialidad frente a los Estados; el debilitamiento democrático en la región; opera en el seno de la OEA, que es un organismo políticamente polarizado y en crisis financiera permanente; la universalización de los tratados interamericanos; el plazo razonable del proceso interamericano, el cumplimiento de las decisiones de los órganos interamericanos, los alcances del control de convencionalidad respecto a su aplicación por toda autoridad pública; los desafíos de la E-justicia desarrollada durante la pandemia. Todo ello provoca el SIDH esté envuelto en un ambiente esclerótico y frecuentemente desfasado frente a las realidades y necesidades del hemisferio.

A tono con lo anterior, la situación para el Sistema se ha complejizado en el último periodo debido a la aparición de la pandemia, al propiciarse una crisis sin precedentes que ha exacerbado las violaciones ya existentes a los derechos humanos, y ha convertido a América
Latina en el nuevo epicentro mundial con el triste resultado de cifras de contagio y fallecidos en constante aumento. Todo esto sin contar las restricciones en la vida pública y la inminente crisis económica que ha impactado con mayor fuerza en la población latinoamericana más pobre y en aquellos que forman parte de la denominada "economía informal".

Según expertos, los países de la región no podrán por sí solos asumir los costes causados por las medidas impuestas, ni amortiguar el impacto de la crisis económica, por lo que dependerán de la ayuda prestada por organizaciones internacionales y países donantes. A pesar de los esfuerzos del Sistema por amortiguar el golpe de la pandemia, mediante la Resolución No.1/2020 y la Declaración No.1/2020, ambas de la Comisión y la Corte respectivamente, hasta la fecha es inevitable el desplome del rendimiento económico, un fuerte ascenso de la pobreza como consecuencia de la crisis del coronavirus, y su detención, que ante su aparición ha acentuado la desigualdad ya existente en América Latina, mediante el denominado "nacionalismo de vacunas".

\section{REFERENCIAS BIBLIOGRÁFICAS}

- Canton, S. A. (2007). El Sistema Interamericano. San José, Costa Rica. Disponible en https://www.ucipfg.com/ Repositorio/MCSH/MCSH-01/Unidad_4/ lecturas-Obligatorias/El_Sistema_ Interamericano_Santiago_Canton.pdf

- Cañelles, M., Jiménez, M. M. y Campillo, N. E. (2021). COVID-19: ¿Cuándo habrá vacunas para todo el mundo? Disponible en https:// n9.cl/ohbws

- CEPAL (2021). "Los efectos del COVID-19: una oportunidad para reafirmar la centralidad de los derechos humanos de las personas migrantes en el desarrollo sostenible". Informe de la Comisión Económica para América Latina y el Caribe de 2021. Disponible en https://n9.cl/wj8ao
- Convención Americana de los Derechos Humanos de 1978. Disponible en: https:// $\mathrm{n} 9 . \mathrm{cl} / \mathrm{mpb} 4 \mathrm{k}$

- Corte IDH (1997). Caso Loayza Tamayo vs. Perú. Fondo. Sentencia de 17 de septiembre de 1997. Serie C N 33.

- Corte IDH (2001). Caso Cantoral Benavides vs. Perú. Reparaciones y Costas. Sentencia de 3 de diciembre de 2001. Serie C N 88.

- Corte IDH (2004). Caso Herrera Ulloa vs. Costa Rica. Excepciones Preliminares, Fondo, Reparaciones y Costas. Sentencia de 2 de julio de 2004. Serie C N 107.

- Corte IDH (2005a). Caso Fermín Ramírez vs. Guatemala. Fondo, Reparaciones y Costas. Sentencia de 20 de junio de 2005. Serie C N 126. 
- Corte IDH (2005b). Caso Raxcacó Reyes vs. Guatemala. Fondo, Reparaciones y Costas. Sentencia de 15 de septiembre de 2005. Serie C N 133;

- Corte IDH (2009a). Caso Dacosta Cadogan vs. Barbados. Excepciones Preliminares, Fondo, Reparaciones y Costas. Sentencia de 24 de Septiembre de 2009. Serie C N 204.

- Corte IDH (2009b) Caso Tristán Donoso vs. Panamá. Excepción Preliminar, Fondo, Reparaciones y Costas. Sentencia de 27 de enero de 2009 Serie C N 193.

- Corte IDH (2009c). Caso Usón Ramírez vs. Venezuela. Excepción Preliminar, Fondo, Reparaciones y Costas. Sentencia de 20 de noviembre de 2009. Serie C N 207.

- Corte IDH (2013a). Caso García Cruz y Sánchez Silvestre vs. México. Fondo, Reparaciones y Costas. Sentencia de 26 de noviembre de 2013. Serie C N 273.

- Corte IDH (2013b). Caso Fontevecchia y D’Amico vs. Argentina. Fondo, Reparaciones y Costas. Sentencia de 22 de agosto de 2013. Serie C N 265.

- Corte IDH (2017). Caso Zegarra Martín vs. Perú. Excepciones Preliminares, Fondo, Reparaciones y Costas. Sentencia de 15 de febrero de 2017. Serie C N 331.

- Corte IDH (2019a). Caso Muelle Flores vs. Perú. Excepciones Preliminares, Fondo, Reparaciones y Costas. Sentencia de 6 de marzo de 2019. Serie C N 375.

- Corte IDH (2019b). Caso Asociación Nacional de CesantesyJubilados de la Superintendencia Nacional de Administración Tributaria vs. Perú. Excepciones Preliminares, Fondo, Reparaciones y Costas. Sentencia de 21 de noviembre de 2019. Serie C N 394.

- Corte IDH (2020). COVID-19 y derechos humanos: los problemas y desafíos deben ser abordados con perspectiva de derechos humanos y respetando las obligaciones internacionales. Declaración de la Corte Interamericana de Derechos Humanos 1/20. Disponible en https://www.corteidh. or.cr/tablas/alerta/comunicado/cp-272020.html

- Cué, F. (2021). Vacunación en América Latina: un comienzo irregular y a paso lento. Disponible en https://n9.cl/4a8u

- De Martini, S., \& Pont, F. (2010). "El Sistema Interamericano de Protección de los Derechos Humanos". En: J. Pérez, Los Derechos Humanos en Latinoamérica. Buenos Aires: Educa.

- Dong, E. Du, H. y Gardner, L. (2020). “An interactive web-based dashboard to track COVID- 19 in real time: Coronavirus COVID-19 Global Cases by the Center for Systems Science and Engineering (CSSE) at Johns Hopkins University (JHU)". The Lancet - Infectious Diseases, 20, (5), pp.: 533-534. doi: https://doi.org/10.1016/ S1473-3099(20)30120-1

- Dunlop, C., Howe, A., Li, D.y, Allen, L.N.(2020). "The coronavirus outbreak: the central role of primary care in emergency preparedness and response". BJGP open. Epub Ahead. DOI: 10.3399/bjgpopen20X101041

- Faúndez, H. (2004). "El sistema interamericano de protección de los derechos humanos: aspectos institucionales y procesales". San José: Ed. IIDH.

- Filgueira, F., Galindo, L.M., Giambruno, C., y Blofield, M. (2020). América Latina ante la crisis del COVID-19: vulnerabilidad socioeconómica y respuesta social. Disponible en https://n9.cl/abjye

- Gallón, G., Monzón , L., Gómez, J., Grossman, C., Goldman, R., Martin, C., RodríguezPinzón, D., Krsticevic, V., Nikken, P., Pinto, M., \& Vannuchi, P. (2007). "Una Revisión Crítica del Sistema Interamericano de Derechos Humanos: Pasado, Presente y Futuro". Anuario de Derechos Humanos, (3). doi:10.5354/0718-2279.2011.13454

- Ibáñez, J. M. (2021). Los nuevos -y no tan nuevos- retos del Sistema Interamericano de Derechos Humanos. Dialogo Derechos Humanos. Agenda Estado de Derecho. 
Disponible en https://n9.cl/9vo2c

- Nash, C. (2020). "Desafíos del sistema interamericano de derechos humanos en tiempos de cólera". Revista Tribuna Internacional, 9(17). doi:10.5354/0719-482X.2020.55276

- Naciones Unidas (2021). Pacto Internacional de Derechos Civiles y Políticos. Disponible en https://www.ohchr.org/sp/ professionalinterest/pages/ccpr.aspx

- Piovesan, F. (2020). "Rol y Medidas de la CIDH para el combate contra la COVID-19". Dialogo Derechos Humanos. Agenda Estado de Derecho. Disponible en https://n9.cl/ hgjbx

- Quispe, F. (2016). "La protección de los derechos humanos en el sistema interamericano: su evolución y una visión actual". Anuario Español de Derecho Internacional. Vol. 32, pp.: 225-258. doi: https://doi.org/10.15581/010.32.225-258

- Resolución no.1/2020. Pandemia y derechos humanos en Las Américas. Sentencia de 10 de Abril de 2020. Costa Rica, Comisión Interamericana de Derechos Humanos, San Jose de Costa Rica. Id SAIJ: FA20570000. Disponible en https://n9.cl/rthbh

- Salvioli, F. (1997). "El desarrollo de la Protección Internacional de los Derechos
Humanos, a partir de las Declaraciones Universal y Americana". Relaciones Internacionales, No. 13, pp.: 77-96. Disponible en http://sedici.unlp.edu.ar/ handle/10915/10067

- Salvioli F. (2020). El Sistema Interamericano de Protección de los Derechos Humanos. Instrumentos, órganos, procedimientos jurisprudencia. Colección Constitución y Derechos. Disponible en https://n9.cl/5pde

- Sánchez, J.A., Arce, L.R., y Rodríguez, A.J. (2020). "Enfermedad por coronavirus 2019 (COVID-19) en América Latina: papel de la atención primaria en la preparación y respuesta". Atención Primaria, Vol. 52 (6), pp.: 369-372. Disponible en: https:// n9.cl/7ncj0

- Tünnermann, C. (1997). Los derechos humanos: evolución histórica y reto educativo. Disponible en https://n9.cl/ px104

- Wu, Z. y McGoogan, J. M. (2020). "Characteristics of and important lessons from the coronavirus disease 2019 (COVID-19) outbreak in China: summary of a report of 72314 cases from the Chinese Center for Disease Control and Prevention". [published online ahead of print, $2020 \mathrm{Feb}$ 24]. JAMA. doi: 10.1001/ jama.2020.2648 